\title{
Correction to: Why Do So Many Economists Underplay the Psychological and Biophysical Aspects of Life on Earth?
}

\section{Michael Jefferson ${ }^{1}$}

Published online: 16 January 2020

(c) Springer Nature Switzerland AG 2020

\section{Correction to: \\ BioPhysical Economics and Resource Quality (2019) 4:15 https://doi.org/10.1007/s41247-019-0064-9}

The original version of this article unfortunately contained two mistakes. On page 4, line 3, the year " 2016 " should read as "1976". On page 9, line 13, the words: "in ant transition" should read as "in any transition".

The original article can be found online at https://doi.org/10.1007/ s41247-019-0064-9.

Michael Jefferson

jeffers@dircon.co.uk

1 ESCP Europe Business School, 527 Finchley Road,

Hampstead, London NW3 7BG, UK 